Gut, 1984, 25, 1089-1092

\title{
Gastrointestinal symptoms in the irritable bowel compared with peptic ulcer and inflammatory bowel disease
}

\author{
W GRANT THOMPSON
}

From the Division of Gastroenterology, Ottawa Civic Hospital, University of Ottawa, Ottawa, Canada

SUMMARY Symptoms of 50 patients with the irritable bowel syndrome were compared with those of 49 with endoscopically proven peptic ulcer disease and 49 with radiologically or endoscopically proven inflammatory bowel disease using a questionnaire which was administered after the diagnosis was made. Symptoms of bowel dysfunction including pain related to bowel movements were more likely to occur in the irritable bowel syndrome than peptic ulcer disease. Only abdominal distension, straining at stool and scybala, however, were significantly more likely in the irritable bowel syndrome than inflammatory bowel disease. Four symptoms previously shown to be more common in irritable bowel syndrome than in organic abdominal disease were combined. The more of these symptoms that were present, the more likely were the patients to have the irritable bowel syndrome than peptic ulcer disease. Symptoms of gut dysfunction are highly discriminating between irritable bowel syndrome and peptic ulcer disease but less so between irritable bowel syndrome and inflammatory bowel disease.

The irritable bowel syndrome has no agreed upon pathophysiologic marker, ${ }^{12}$ and suggested physical signs have not been authenticated. ${ }^{3}$ Therefore this very common disorder can only be recognised by its symptoms and identified by the exclusion of organic disease. In a previous study four symptoms were more likely to be found in the irritable bowel syndrome than in a number of organic gastrointestinal conditions. ${ }^{4}$ As the numbers of patients with specific gastrointestinal diseases in this study were small, it was not possible to determine how discriminating the four symptoms were in distinguishing individual abdominal gastrointestinal diseases from the irritable bowel syndrome.

The present study compares the prevalence of these and other gut symptoms in patients with the irritable bowel syndrome with that in two specific organic diseases affecting different parts of the gut; peptic ulcer disease and inflammatory bowel disease. It is important to know the extent to which historic features discriminate between these very common conditions as it is frequently on the basis of symptoms that diagnostic tests are ordered. As

\footnotetext{
Address for correspondence: Professor W Grant Thompson, Division of Gastroenterology, A1, Ottawa Civic Hospital, 1053 Carling Avenue, Ottawa, Canada K1Y 4E9.

Received for publication 11 January 1984
}

abdominal pain and/or altered bowel habit affect about $30 \%$ of the population, ${ }^{5}$ and up to one-third of outpatient gastrointestinal referrals ${ }^{6}$ a complete investigation of the gut cannot be contemplated in everyone. Symptoms suggesting organic disease such as gastrointestinal haemorrhage, bloody diarrhoea, weight loss and fever indicate a need for thorough radiographic and endoscopic intervention, but many patients with organic disease do not present such obvious pointers to the physician. The following is a study of the discriminating power of a variety of gut symptoms in permitting a positive diagnosis of the irritable bowel syndrome and which in the absence of organic symptoms might reduce the suspicion of peptic ulcer disease or inflammatory bowel disease. If symptoms can be identified which indicate a high probability of irritable bowel syndrome, unnecessary tests may be avoided and patient management expedited.

\section{Methods}

\section{PATIENTS}

One hundred and forty eight consecutive patients referred to the author via clinic or emergency were included in the study when a diagnosis of the irritable bowel syndrome, peptic ulcer or inflam- 
matory bowel disease had been established. (Table 1) Fifty patients with irritable bowel syndrome had altered bowel habit with or without abdominal pain. Those with painless diarrhoea were not included. The patients were all newly referred and the diagnosis remained unchanged after a return visit six weeks later.

Forty nine peptic ulcer patients were diagnosed endoscopically after complaining of dyspepsia or presenting with a gastrointestinal haemorrhage. There were 33 with a duodenal ulcer and 16 with a gastric ulcer. Forty nine patients had inflammatory bowel disease. Of these, 29 had ulcerative and nine had Crohn's colitis proven by sigmoidoscopy, biopsy, and negative cultures. A further 11 had radiographically proven Crohn's disease confined to the small bowel. Some inflammatory bowel disease patients were new, and others were seen during exacerbations of their illness.

Overall, there were 68 men and 80 women whose mean age was 43 and 42 years respectively. The age and sex distributions for each disease are shown in Table 1. There were more women in the irritable bowel syndrome group than in the other two groups. The mean age was similar in men and women, but the inflammatory bowel disease group was younger.

Patients who had previous gastric or bowel surgery were excluded. All patients had a rectal examination and those with irritable bowel syndrome or inflammatory bowel disease underwent rigid or fibreoptic sigmoidoscopic examination. At an interview subsequent to establishment of the diagnosis, the author asked each patient the questions on a questionnaire and filled in the appropriate responses. The possibility of bias is acknowledged, but minimised by the number and variety of the questions. The patient did not know the object of the questionnaire and answers were not prompted by the interviewer. The questions dealt with abdominal gastrointestinal symptoms (Table 2). A symptom was said to be 'infrequent' if it occurred one or more times in the previous 12 months. The symptom was 'frequent' when present more than $25 \%$ of days or occasions.

The data were stored on a diskette by means of a
Radio Shack Model III microcomputer. Data management was accomplished using a statistical package for the social sciences (SPSS) called STATPAC, adapted for the microcomputer by Walonick and Associates of Minneapolis. Analysis included frequency distribution, Student's $t$ test, cross tabulation, and $\chi^{2}$ analysis with the Yates correction for continuity applied. A special program called 'Combine' (Walonick) was used to determine the number of persons in each group with $0,1,2,3$, and 4 symptoms.

\section{Results}

The occurrence of specific gut symptoms during the year before the interview is summarised in Table 2 . Their incidence in the irritable bowel syndrome is compared with that in peptic ulcer and in inflammatory bowel disease. The significance of any differences is indicated between the columns. Note that disturbances of defaecation were much more common in irritable bowel syndrome than in peptic ulcer and when pain was present it was much more likely to be related to bowel function. Note also that the four symptoms previously shown to be significantly more frequent in the irritable bowel syndrome than in organic abdominal disease are far more likely to occur (infrequent and frequent) in the irritable bowel syndrome than in peptic ulcer disease. These four symptoms are abdominal distension, pain relieved by defaecation, looser stools with pain onset, and more frequent stools with pain onset. ${ }^{3}$ For the purpose of this study, diarrhoea may be defined as loose or watery stools on more than $25 \%$ of occasions (frequent) and constipation as straining at stool on more than $25 \%$ of occasions (frequent $)^{4}$. Both were more likely in irritable bowel syndrome than peptic ulcer disease.

On the other hand the prevalence of disturbances of defaecation was similar in irritable bowel syndrome and inflammatory bowel disease. Among the four previously studied irritable bowel syndrome symptoms, only abdominal distension was more frequent in the irritable bowel syndrome group. The reduced incidence of scybala and straining at stool in

Table 1 Characteristics of study patients

\begin{tabular}{|c|c|c|c|c|c|c|c|c|}
\hline & \multirow[b]{2}{*}{ No } & \multirow[b]{2}{*}{ Women } & & & \multicolumn{2}{|l|}{ Age } & & \multirow[b]{2}{*}{$p$} \\
\hline & & & & & Range & Mean & & \\
\hline Irritable bowel syndrome & 50 & $39(78 \%)\}$ & \multirow{3}{*}{$\left.\begin{array}{l}p<0.001 \\
p<0.05\end{array}\right\}$} & \multirow{3}{*}{$\mathrm{p}<0.01$} & $20-72$ & $44\}$ & NS & \multirow{3}{*}{$\mathrm{p}<0.001$} \\
\hline Peptic ulcer & 49 & $15(31 \%)\}$ & & & $17-87$ & 50\{ & & \\
\hline Inflammatory bowel disease & 49 & $26(53 \%)\}$ & & & $14-70$ & $32\}$ & $\mathrm{p}<0 \cdot 001$ & \\
\hline
\end{tabular}


Symptoms in the irritable bowel, peptic ulcer, and inflammatory bowel disease

Table 2 Bowel symptoms in irritable bowel syndrome, peptic ulcer disease, and inflammatory bowel disease

\begin{tabular}{|c|c|c|c|c|c|c|}
\hline $\begin{array}{l}\text { Symptom } \\
\text { (all patients) }\end{array}$ & Occurrence & $\begin{array}{l}\text { Peptic ulcer } \\
(n=49)(\%)\end{array}$ & $p$ & $\begin{array}{l}\text { Irritable bowel } \\
\text { syndrome } \\
(n=50)(\%)\end{array}$ & $p$ & $\begin{array}{l}\text { Inflammatory } \\
\text { bowel disease } \\
(n=49)(\%)\end{array}$ \\
\hline \multirow[t]{2}{*}{ Abdominal distension* } & infrequent & 55 & $\mathrm{p}<0.005$ & 84 & $\mathrm{p}<0.01$ & 59 \\
\hline & frequent & 20 & $\mathrm{p}<0.02$ & 42 & $\mathrm{p}<0.001$ & 10 \\
\hline \multirow[t]{2}{*}{ Mucus in stool } & infrequent & 20 & $\mathrm{p}<0.001$ & 60 & NS & 71 \\
\hline & frequent & 6 & $p<0.05$ & 20 & NS & 24 \\
\hline \multirow[t]{2}{*}{ Incomplete evacuation } & infrequent & 61 & $\mathrm{p}<0.005$ & 88 & NS & 73 \\
\hline & frequent & 8 & $\mathrm{p}<0.002$ & 24 & NS & 31 \\
\hline \multirow[t]{2}{*}{ Scybala } & infrequent & 51 & $\mathrm{p}<0.002$ & 82 & $\mathrm{p}<0.001$ & 31 \\
\hline & frequent & 16 & NS & 32 & $\mathrm{p}<0.002$ & 6 \\
\hline \multirow[t]{2}{*}{ Urgent stools } & infrequent & 45 & $\mathrm{p}<0.01$ & 72 & NS & 76 \\
\hline & frequent & 13 & $\mathrm{p}<0.01$ & 34 & NS & 29 \\
\hline \multirow[t]{2}{*}{ Watery stool } & infrequent & 29 & $\mathrm{p}<0.05$ & 37 & NS & 35 \\
\hline & frequent ${ }^{\dagger}$ & 4 & $\mathrm{p}<0.01$ & 22 & NS & 19 \\
\hline \multirow[t]{2}{*}{ Straining at stool } & infrequent & 31 & NS & 40 & $\mathrm{p}<0.001$ & 27 \\
\hline & frequent $\ddagger$ & 9 & $\mathrm{p}<0.04$ & 18 & NS & 11 \\
\hline Abdominal pain & $6 \times / y r$ & 75 & NS & 88 & $\mathrm{p}<0.001$ & 55 \\
\hline \multirow{2}{*}{\multicolumn{2}{|c|}{$\begin{array}{l}\text { PATIENTS WITH PAIN } \\
\text { Below navel }\end{array}$}} & \multicolumn{2}{|l|}{$(n=37)$} & \multicolumn{2}{|l|}{$(n=44)$} & $(n=27)$ \\
\hline & & 8 & $\mathrm{p}<0.001$ & 73 & NS & 81 \\
\hline Pain relief with & infrequent & 33 & $p<0.001$ & 82 & NS & 78 \\
\hline bowel motion* & frequent & 19 & $\mathrm{p}<0.001$ & 68 & NS & 67 \\
\hline \multirow{2}{*}{\multicolumn{2}{|c|}{ Pain ${ }^{*}$ - altered frequency }} & 27 & $\mathrm{p}<0.005$ & 61 & NS & 52 \\
\hline & & 19 & $\mathrm{p}<0.05$ & 41 & NS & 41 \\
\hline \multicolumn{2}{|l|}{ Pain* - altered consistency } & 30 & $\mathrm{p}<0.005$ & 64 & NS & 48 \\
\hline \multirow{3}{*}{$\begin{array}{l}\text { - looser consistency } \\
\text { Pain relief with flatus }\end{array}$} & & 14 & $\mathrm{p}<0.02$ & 37 & NS & 33 \\
\hline & infrequent & 35 & $\mathrm{p}<0.02$ & 64 & NS & 66 \\
\hline & frequent & 16 & NS & 25 & NS & 26 \\
\hline
\end{tabular}

* Symptoms associated with irritable bowel syndrome (3). + Diarrhoea (5). $¥$ Constipation (5).

Infrequent $=<25 \%$ of occasions or days. Frequent $=>25 \%$ of occasions or days.

inflammatory bowel disease reflects a reduced tendency to constipation. Abdominal pain was less frequent in the inflammatory bowel disease than irritable bowel syndrome but among those with pain its characteristics were similar in the two groups.

The Figure compares the discrimination between the three conditions that can be achieved by adding symptoms together. Using the four symptoms which in a previous study were significantly more common in irritable bowel syndrome than organic disease, ${ }^{3}$ the patients in each group with 0,1 or more, 2 or more, 3 or more and 4 of them are compared. The symptoms are abdominal distension, pain relieved by defaecation, more frequent stools with pain onset, and looser stools with pain onset. Forty seven, or $96 \%$ of irritable bowel syndrome subjects had one or more of these symptoms which was greater than in peptic ulcer $(p<0.002)$ or inflammatory bowel disease $(p<0.005)$. If two or more symptoms are present, the differences between irritable bowel syndrome and peptic ulcer or inflammatory bowel disease are very highly significant $(p<0 \cdot 0001)$. These combinations of symptoms more effectively differentiate irritable bowel syndrome from peptic ulcer disease than inflammatory bowel disease.

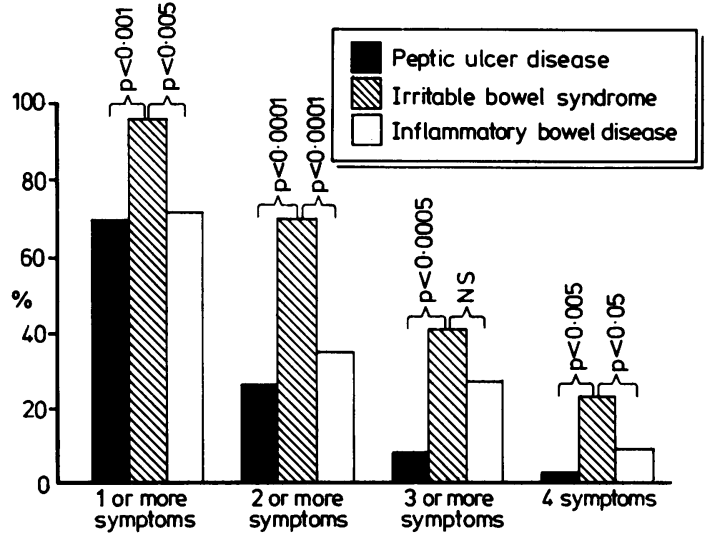

Figure Cumulative symptoms in patients with peptic ulcer disease, irritable bowel syndrome, and inflammatory bowel disease. Four symptoms previously shown to be more frequent in the irritable bowel syndrome than in organic abdominal disease are: abdominal distension, pain relief with defaecation, looser and more frequent bowel movements with onset of pain. ${ }^{3}$ Shown are the percentage of patients in each condition who have one or more, two or more, three or more, or four of these four symptoms. 


\section{Discussion}

The irritable bowel syndrome consists of abdominal pain and/or disordered bowel habit. Its diagnosis depends on exclusion of abdominal organic disease, although studies have attempted to point out positive features in the history and physical examination. $^{34}$ A previous study indicated that among patients presenting to clinic with abdominal pain and/or altered bowel habit, four symptoms were significantly more common in the irritable bowel syndrome than in organic abdominal disease. ${ }^{4}$ In the organic group, however, the numbers of patients with specific diseases were small, so the discriminating power of the symptoms could not be determined for individual diseases, or diseases occurring in similar and different parts of the gastrointestinal tract.

In the present study, symptoms were elicited by a questionnaire in 50 patients with irritable bowel syndrome, 49 with proven peptic ulcer and 49 with radiographically or endoscopically proven inflammatory bowel disease after the diagnosis was made. The results indicate that these symptoms are highly discriminating features of irritable bowel syndrome when compared with peptic ulcer disease. When compared with inflammatory bowel disease, irritable bowel syndrome patients were much more likely to have distension, but not the other three symptoms. Other bowel symptoms such as mucus, incomplete evacuation, scybala, straining at stool, watery stools, urgent stools, and pain relieved with passing flatus were also more frequent in the irritable bowel syndrome than peptic ulcer disease. Among these other features only abdominal distension, scybala and straining were more frequent in irritable bowel syndrome than inflammatory bowel disease. When so many statistical comparisons are done, some differences may be due to chance. This may mean that the few symptoms that are different between irritable bowel syndrome and inflammatory bowel disease are spurious. With so many differences shown between irritable bowel syndrome and peptic ulcer disease, however, the symptomatology in these two conditions must be truly different. The presence of one or more, or better two or more, of the four symptoms previously noted to be discriminating, ${ }^{4}$ is more likely in irritable bowel syndrome than peptic ulcer. Cumulation of these symptoms is less likely to discriminate irritable bowel syndrome from inflammatory bowel disease. Evidence has been presented elsewhere that irritable bowel syndrome symptoms are frequent in ulcerative colitis in remission. ${ }^{7}$

Thus symptoms of bowel dysfunction and association of pain to defaecation are highly discriminating features of the irritable bowel syndrome when compared with peptic ulcer disease but less so when compared with inflammatory bowel disease. This discrimination is better the greater the number of symptoms present.

Thus the presence of the symptoms listed in Table 2 in the absence of bleeding or meal related epigastric pain relieved by food or antacid should help the physician choose irritable bowel syndrome rather than peptic ulcer disease. As might be anticipated in two diseases affecting the large and small bowel, they are less helpful in separating irritable bowel syndrome from inflammatory bowel disease and some colon procedure(s) will be necessary. Careful questioning with attention to these symptoms, however, should allow a more precise investigation of suspected irritable bowel syndrome patients that does not in most instances include upper gastrointestinal endoscopy, upper gastrointestinal tract imaging or the use of anti-ulcer medication. As nearly half the outpatients referred to gastroenterologists have functional disorders, ${ }^{6}$ the cost of a complete gastrointestinal investigation in all of them could be enormous. Therefore the search for positive indicators of the irritable bowel syndrome should continue.

This study was supported by a grant from the Ottawa Civic Hospital Foundation. Manuscript prepared with the assistance of Mrs Mary Anne LaSalle, Medical Records, Ottawa Civic Hospital, and Drs J E Devitt, $R$ Nair and $R$ A Spasoff provided helpful advice.

\section{References}

1 Thompson WG. The irritable gut. Baltimore: University Park Press, 1979.

2 Thompson WG. Progress report: the irritable bowel. Gut 1983; 24: 305-20.

3 Fielding JF. The diagnostic sensitivity of physical signs in the irritable bowel syndrome. Irish Med J 1981; 74: $143-4$.

4 Manning AP, Thompson WG, Heaton KW, Morris A. Towards positive diagnosis of the irritable bowel. $\mathrm{Br}$ Med J 1978; 2: 653-4.

5 Thompson WG, Heaton KW. Functional bowel symptoms in apparently healthy people. Gastroenterology 1980; 79: 283-8.

6 Harvey RF, Salih SY, Read EA. Organic and functional disorders in 2000 gastroenterology outpatients. Lancet 1983; 1: 632-4.

7 Isgar B, Harman M, Kaye MO, Whorwell PJ. Symptoms of irritable bowel syndrome in ulcerative colitis in remission. Gut 1983; 24: 190-2. 